\title{
Odontogenic Keratocyst Tumor: Report of Two Cases
}

\author{
Tumor Queratoquiste Odontogénico: Reporte de dos Casos \\ Ellen Cristina Gaetti Jardim*; Ana Cláudia Rossi"; Leonardo Perez Faverani*; Gabriel Ramalho Ferreira*; \\ Mayara Barbosa Ferreira*; Larissa Martini Vicente* \& Idelmo Garcia Rangel Júnior*
}

JARDIM, E. C. G.; ROSSI, A. C.; FAVERANI, L. P.; FERREIRA, G. R.; FERREIRA, M. B.; VICENTES, L. M. \& JÚNIOR, I. G. R. Odontogenic keratocyst tumor: report of two cases. Int. J. Odontostomat., 7(1):33-38, 2013.

ABSTRACT: In 2005, odontogenic cyst was classified as keratocyst odontogenic tumor due to being aggressive and recurrent. The keratocyst odontogenic tumor has characteristics, with slow development, does not cause metastases and provides great bone destruction. The aim of this study was to discuss the aspects regarding the diagnosis, prognosis and treatment of odontogenic keratocyst tumor, through the report of two cases. Both initially underwent decompression of the lesion present proximity of anatomical structures to be great and noble, aiming to prevent pathological fractures. We carried out the clinical-radiographic and after regression of the lesion, patients underwent enucleation total.

KEY WORDS: odontogenic keratocyst, keratocystic odontogenic tumor, orthokeratinized odontogenic keratocyst, orthokeratinized odontogenic cyst.

\section{INTRODUCTION}

The etiology of odontogenic keratocyst tumor (KCOT) consists of the remnants of dental lamina (Philipsen, 1956). Matches 3 to $11 \%$ of odontogenic cysts (Brannon, 1976; Chuong et al., 1982). Recognized by WHO in 2005 as odontogenic keratocyst tumor, the lesion has an aggressive nature, with high recurrence rates, tumor characteristics, slow growth, does not cause metastasis and bone destruction generates (Barnes et al., 2005). Showed a predominance of males, and aged between 20 and 40 years (Kolokhytas et al., 2007).

Clinically, KCOT characterized by a single lesion, with greater frequency in the region of branch location and angle of the jaw. It is generally asymptomatic, being discovered on routine radiographic examination. However, when it reaches major proportions, can display poor positioning of the teeth, swelling due to expansion of cortical spontaneous drainage of the cystic content in the oral cavity and also complaining of pain in cases of secondary infection of the lesion (Maurette et al., 2006).
Radiographically can be observed in a multior unilocular, well-defined margin, rarely causing root resorption, except in syndrome nevoid basal cell carcinoma, which may be associated with multiple keratocysts, along with cutaneous nevi, basal cell carcinomas, rib anomalies, among other manifestations of the syndrome characteristics (Donatsky et al., 1976).

There has specific characteristics, then, other cystic lesions and cancer are included in the differential diagnosis, such as lateral periodontal cyst, traumatic bone cyst, central giant cell tumor, radicular cyst, ameloblastoma, a benign bone tumor and adenomatoid odontogenic tumor (Giuliani et al., 2006).

The diagnosis of KCOT may only be obtained by biopsy and histopathological analysis. Has a stratified epithelium lining, typically thin and uniform thickness free of inflammation, and with corrugated parakeratinized. The basal layer of the lesion is well defined cuboidal or columnar cells with palisading (Leite et al., 2011).

\footnotetext{
* Department of Surgery and Integrated Clinics, Faculty of Dentistry of Araçatuba, Paulista State University (UNESP), Araçatuba, SP, Brazil.

** Department of Morphology, Piracicaba Dental School, State University of Campinas, Piracicaba, SP, Brazil.
} 
The approaches taken to the surgical treatment of KCOT involved since conservative choice to the more aggressive. Treatments may be a simple enucleation held in a single surgical procedure; marsupialization, which consists of a store to open surgical suturing the wall injury to the epithelium of the oral mucosa; the decompression, which differs from marsupialization by installing a device for progressive reduction in size keratocyst; enucleation associated curettage; the application of Carnoy's solution or cryotherapy; excision block and graft bone resection immediate (Maurette et al.).

Thus, the aim of this study was to discuss the aspects regarding the diagnosis, prognosis and treatment of KCOT, through the report of two cases.

\section{CASE REPORT}

Case 1. Caucasian patient, male, 18 years old, sought care in outpatient Oral and Maxillofacial surgery, Faculty of Dentistry, Araçatuba - UNESP, São Paulo, Brazil. In the extraoral exam observed swelling in the left side with an evolution time of 3 days (Fig. 1). According to the patient, the swelling have appeared after a trauma to the gingival mucosa bottom and back on the same side of a herringbone. In the panoramic radiograph revealed a lesion involving the radiolucent periapical region of tooth 37 (Fig. 2). Was coronal opening of the tooth 37 (Fig. 3) and installing dressing endodontic being prescribed antibiotics (500 $\mathrm{mg}$ amoxicillin, each 8 hours for 7 days, po) and anti-inflammatory (Nimesulide 100 mg, each 12 hours for 4 days, po).
In the second assessment, because of swelling and drainage of pus through tooth channel, were performed under local anesthesia, intraoral drainage and installation of penrose drain (Fig. 4). After two days of drainage and evaluation of panoramic radiography, it was observed injury involving large radiotransparent periapex all of the teeth 36 and 37 , extending to the portion of mandibular angle, and left with halo radiopaque well defined (Fig. 5).

As a treatment plan, we opted for decompression of the lesion under local anesthesia. After blocking the inferior alveolar nerve, lingual and buccal proceeded to a circular incision in the retromolar and buccal tooth 37 , involving up to periosteum, osteotomy with bur and abundant irrigation and removal of circular form to access this portion of the capsule coating of the lesion. Part of the capsule was removed in circular form for microscopic examination, and for decompression, we used a latex device, from medicinal dropper. Portion dropper itself was removed to promote communication between the internal environment of the lesion and the oral cavity. The suture was performed with simple interrupted points (4-0 silk, Ethicon $\circledast$ ) around the circumference of the device.

Prescribed, in the postoperative period were, Amoxicillin 500 mg each 8 hours for 7 days, Nimesulide $100 \mathrm{mg}$ each 12 hours for 5 days and Dipyrone $500 \mathrm{mg}$, 35 drops every 6 hours in case of pain.

Patients were instructed to irrigate the cavity daily with chlorhexidine $0.12 \%$ during the first fifteen days and, subsequently, with conventional mouthwash without alcohol solution.

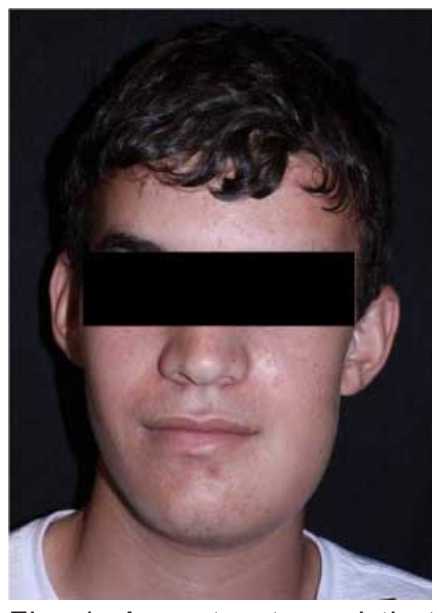

Fig. 1. Aspect extraoral that observed swelling in the left side with an evolution time of 3 days.

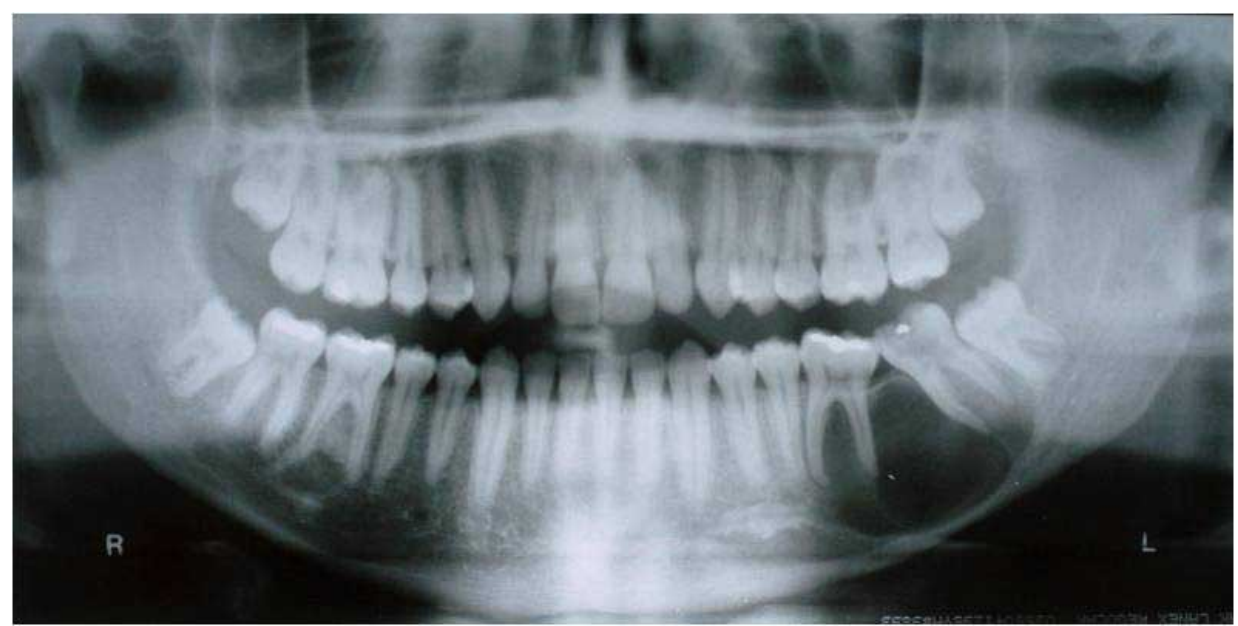

Fig. 2. Panoramic radiograph revealed a lesion involving the radiolucent periapical region of tooth 37 . 


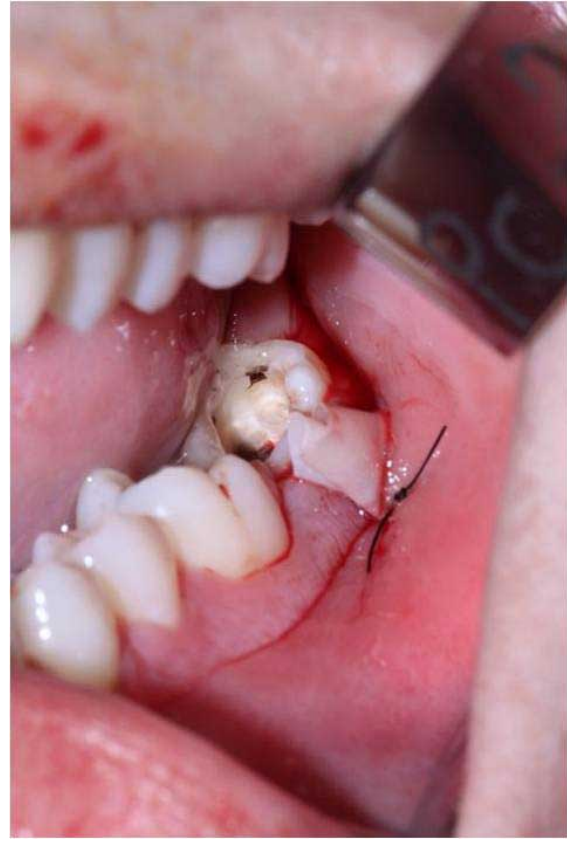

Fig. 3. Coronal opening of the tooth 37.

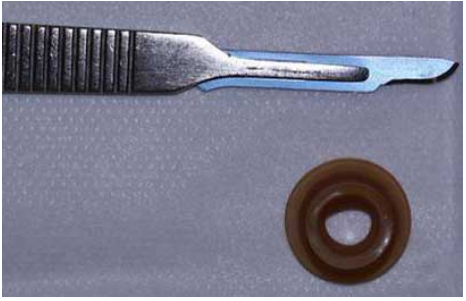

Fig. 4. Intraoral drainage and installation of penrose drain.

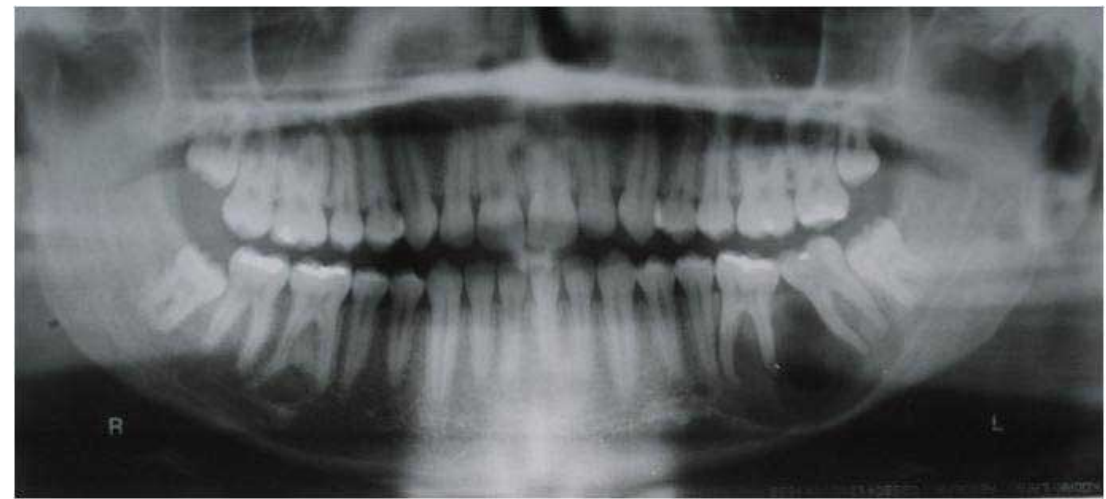

Fig. 5. Panoramic radiography showed injury involving large radiotransparent periapex all of the teeth 36 and 37, extending to the portion of mandibular angle, and left with halo radiopaque well defined.
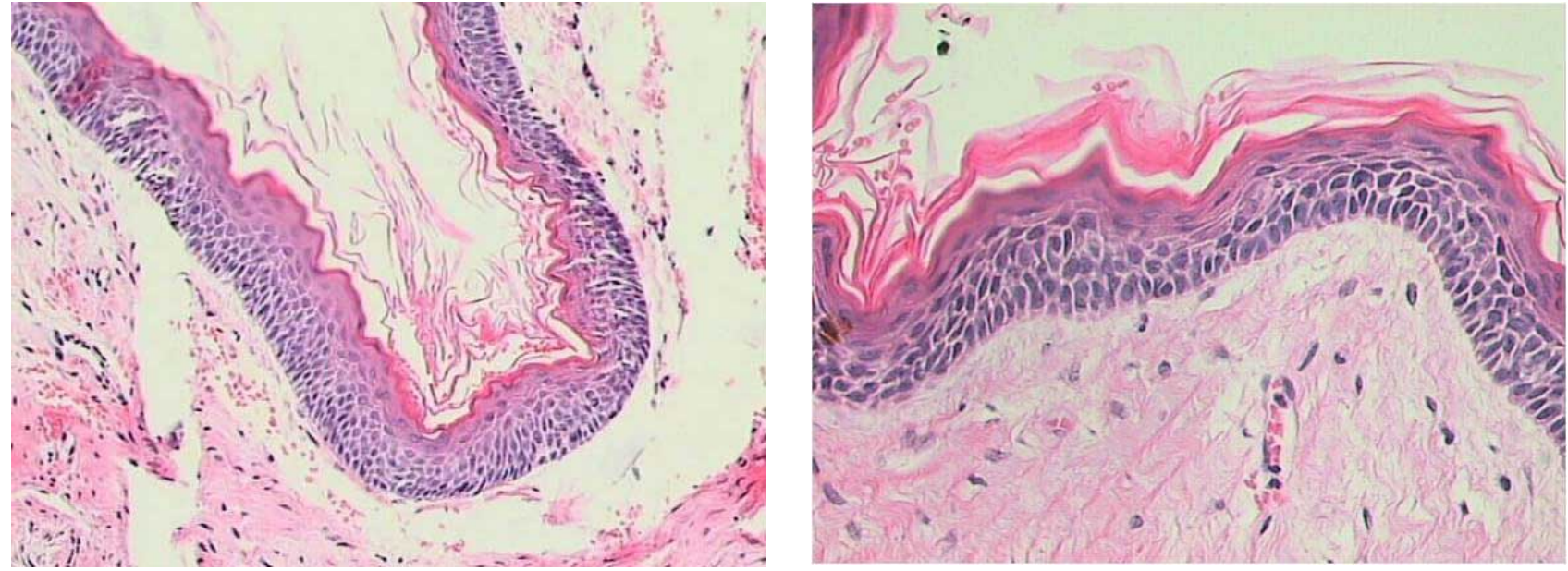

Figs. 6 and 7. Parakeratinized epithelium with prominent palisade basal cell layer and corrugated surface (H\&E staining, original magnification $\times 4$ ).

Microscopic examination showed cystic cavity filled with parakeratinized debris stratified squamous epithelium and cystic fibrous capsule with no inflammatory cells, with confirmed diagnosis of KCOT (Figs. 6 and 7).

The clinical follow-ups were performed weekly in the first 4 weeks and then monthly until 4 months. With the decrease in internal pressure of a decompression injury was significant, proposed four months after enucleation of the lesion under local anesthesia. It is noteworthy that during treatment, the patient was referred for endodontic treatment of teeth 36 and 37 , both involved by the lesion.

The patient is under clinical-imaging, every six months for a period of five years because of recurrence rate seen in these tumors. 
Case 2. Caucasian patient, 45 year-old, male, sought care in outpatient Oral and Maxillofacial Surgery, Faculty of Dentistry, Araçatuba-UNESP, São Paulo, Brazil, reporting that in a routine dental visit, a lesion was identified in the mandible. During extraoral examination, no changes (Fig. 8). On intraoral examination, there was expansion of buccal cortex in the posterior mandibular left and panoramic radiograph examination, there was radiolucent lesion involving the periapical region 37 , extending up angle, and branch near the notch in the jaw (Fig. 9).

As a treatment plan, we opted for decompression of the lesion under general anesthesia. As in the first case, after the inferior alveolar nerve block, lingual and buccal, we proceeded with the implementation of a circular incision in the retromolar and buccal tooth 37 , involving up to periosteum, checking cortical bone access. Access was expanded from a circular shape, with osteotomy using drill under copious irrigation (Fig. 10). After removal of the capsule for decompression and collecting the same for histopathological analysis, was used, similar to the previous case, a latex device from medicinal dropper. Promoted to suture simple interrupted stitches (Nylon 4-0 - Johnson \& Johnson Company) around the circumference of the device (Fig. 11). Prescribed postoperatively are Amoxycillin $500 \mathrm{mg}$ each 8 hours for 7 days, Nimesulide $100 \mathrm{mg}$ each 12 hours for 5 days and Dipyrone $500 \mathrm{mg}, 35$ drops each 6 hours in case of pain. The patient was instructed to perform daily irrigations with chlorhexidine $0.12 \%$ during the fifteen days early, and conventional mouthwash without alcohol solution after this period.

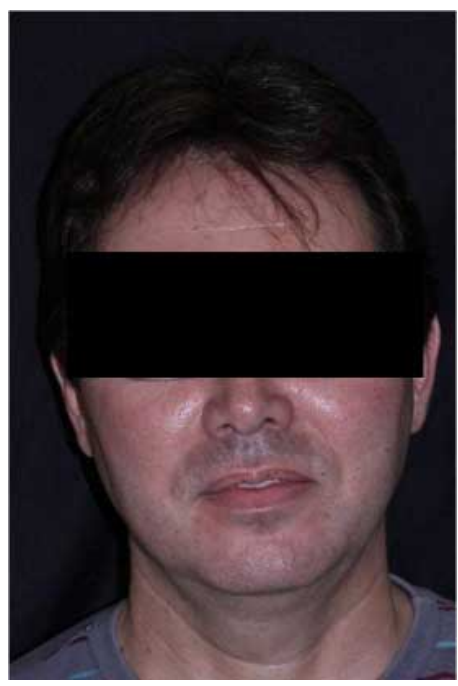

Fig. 8. Aspect extraoral with any alterations.
Microscopic analysis showed cystic epithelium is stratified squamous parakeratinized containing 8-10 cell layers, corrugated surface and interface with the flat connective capsule. The capsule had mild chronic inflammatory infiltrate; the diagnosis was confirmed in KCOT (Figs. 12 and 13).

After the clinical follow-ups weekly, during the first four weeks and monthly until at least 4 months, it was found to decrease the internal pressure of the lesion, as well as reducing its proportions and bone formation, observed by X-ray examinations (Fig. 14). Subsequently the enucleation of the lesion was performed under local anesthesia. The clinical and radiographic follow-up of 10 months shows complete disappearance of decompression injury, replaced by bone tissue, and the same place every six months, for a period of five years, to control the case.

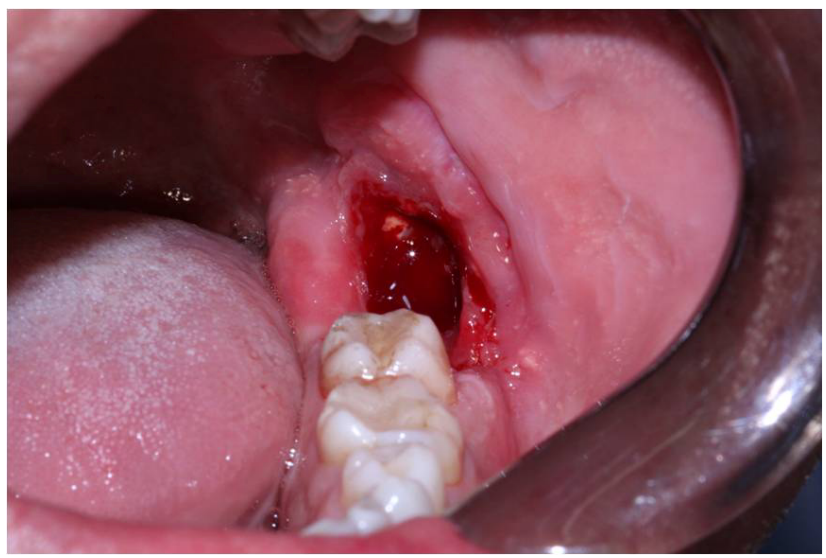

Fig. 10. Access was expanded from a circular shape, with osteotomy.

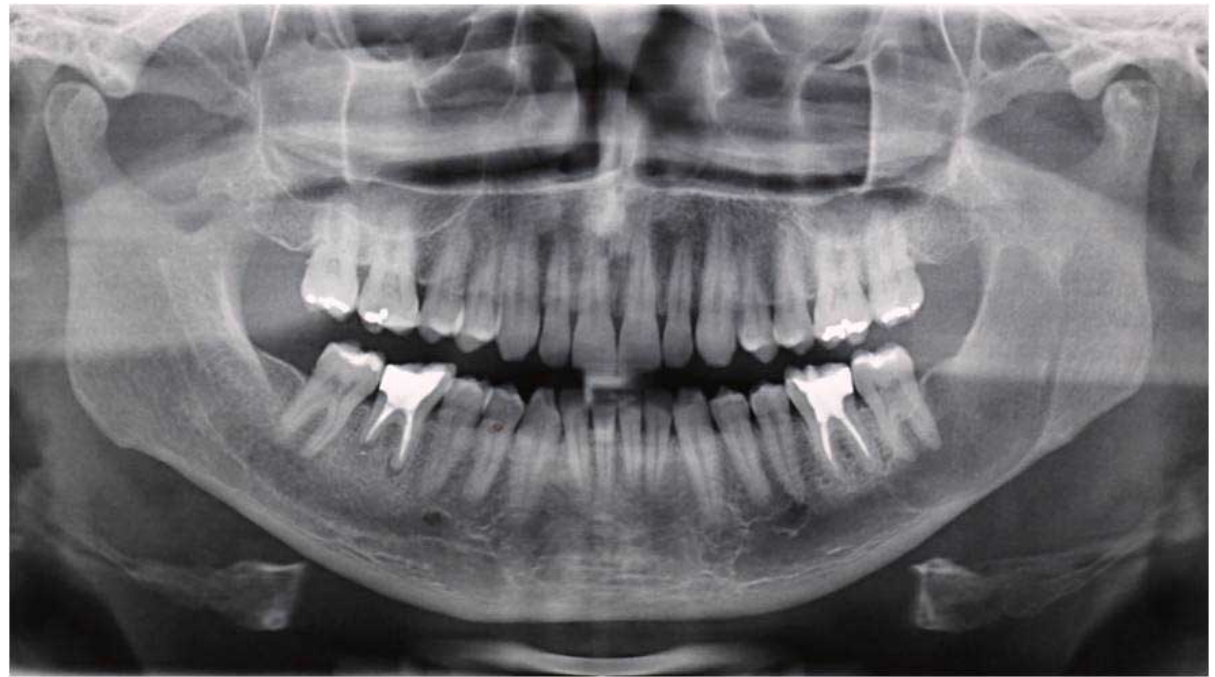

Fig. 9. Panoramic radiograph examination with radiolucent lesion involving the periapical region 37 , extending up angle, and branch near the notch in the jaw. 


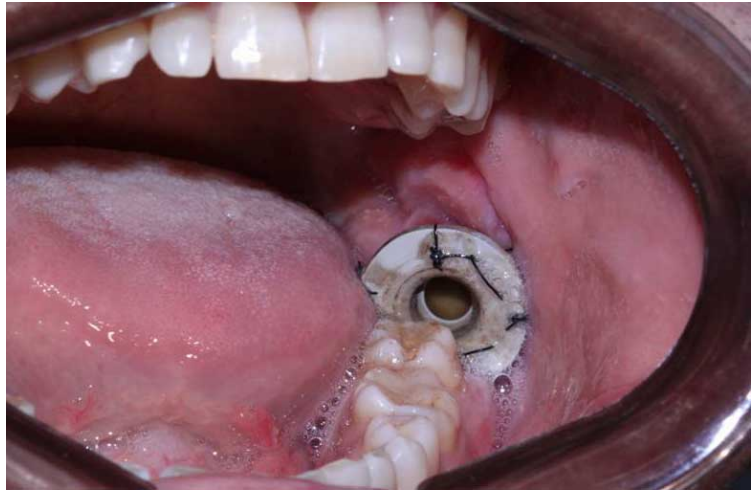

Fig. 11. Intraoral drainage and installation of penrose drain.

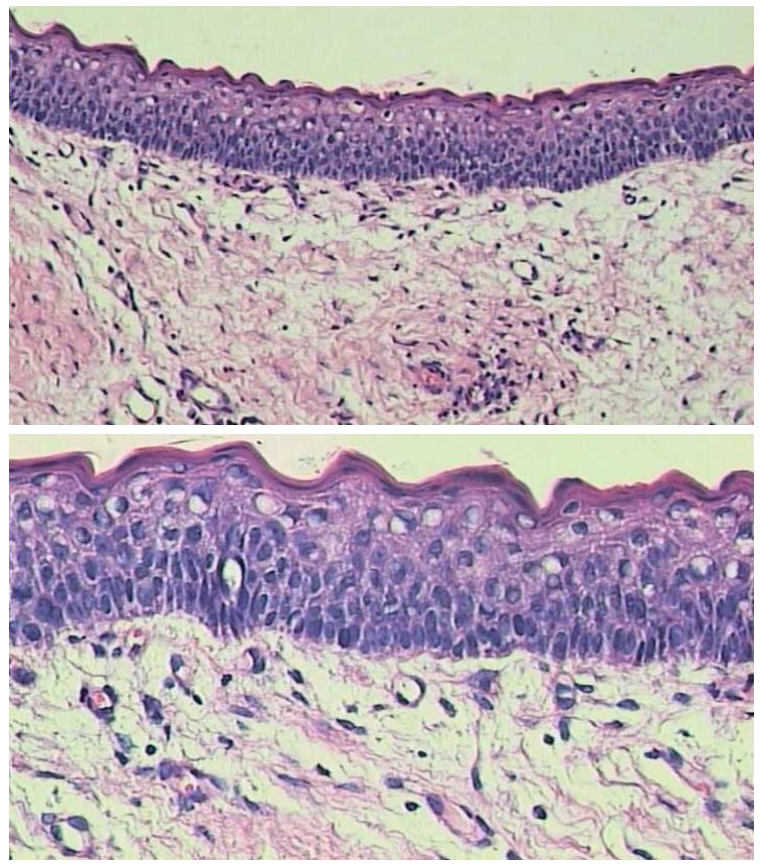

Figs. 12 and 13. Parakeratinized epithelium with prominent palisade basal cell layer and corrugated surface (H\&E staining, original magnification $\times 4$ ).

\section{DISCUSSION}

The presence of symptoms was observed only in one case in which the patient complained of swelling in the face, justified by the trauma and subsequent infection of the lesion. After treatment performed for drainage and resolution of infection an extensive radiolucent area was observed in the left mandible. The latter patient had no symptoms, and confirmed the presence of lesions in routine radiographic examination, which often contribute to discovering KCOT asymptomatic cases. The absence of symptoms is probably related to the growth pattern of the tumor, which tends to reach a considerably large size before causing expansion of the cortical bone. As in other studies, the most common symptom was swelling (Myoung et al., 2001).

Clinically, both patients had attended, intraoral exam, increased volume in the posterior left mandible, and only the first volume had increased headgear, due to secondary infection. Radiographic analysis the two cases showed extensive radiolucent lesion involving the periapical region of the posterior teeth and extending to the region and the mandibular angle. It is important to note that the most common area was the body and/or ramus of the mandible and the tumor tends to grow predominantly in the anterior-posterior direction in the mandible, which allows it to reach large sizes, without causing significant bone expansion (Oda et al., 2000).

The diagnosis of KCOT can be performed by biopsy followed by histopathologic examination or even aspiration biopsy followed by protein determination and / or cytology (Mendes et al., 2010).

The search for conservative treatment to preserve the most structures of the face has been developed with the study of various techniques for therapeutic approach, since KCOT normally has a slow growth and metastases without generating.

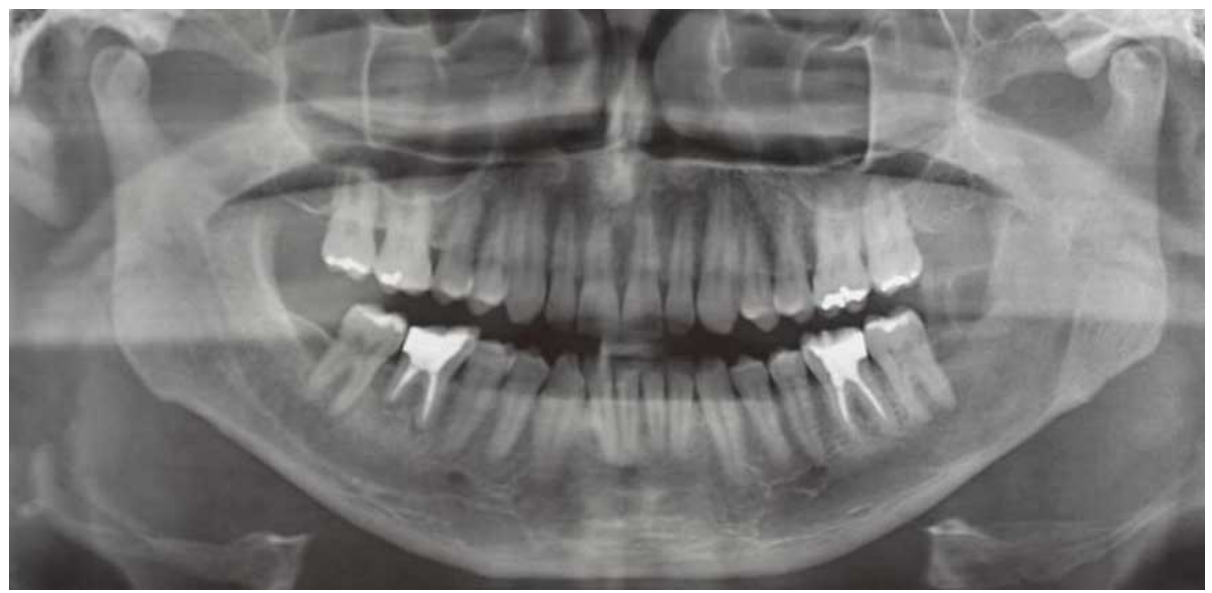

The analysis and conduct obtained in cases presented allow complete the importance of histopathology associated with imaging and clinicians to KCOT correct diagnosis, and the success of the therapeutic approach conservative performed, resulting in complete resolution of cases, and the preservation of structures with good prognosis of these lesions. 
JARDIM, E. C. G.; ROSSI, A. C.; FAVERANI, L. P.; FERREIRA, G. R.; FERREIRA, M. B.; VICENTES, L. M. \& JÚNIOR, I. G. R. Tumor queratoquiste odontogénico: Reporte de dos casos. Int. J. Odontostomat., 7(1):29-32, 2013.

RESUMEN: El año 2005 quiste odontogénico fue clasificado como un tumor queratoquiste odontogénico (TQO) debido a su agresividad y recurrencia. EI TQO tiene las características del tumor: crecimiento lento, no causa metástasis y proporciona una gran destrucción ósea. El objetivo de este estudio fue examinar los aspectos relacionados con el diagnóstico, pronóstico y tratamiento del TQO mediante la presentación de dos casos. Ambos casos fueron inicialmente sometidos a descompresión debido al gran tamaño de la lesión y la proximidad de ésta con estructuras anatómicas importantes, con el objetivo de prevenir las fracturas patológicas. Se llevó a cabo un seguimiento clínico-radiográfico y después de tener una regresión de la lesión postdescompresión, los pacientes fueron sometidos la enucleación total.

PALABRAS CLAVE: queratoquiste odontogénico, tumor odontogénico queratoquistico, queratoquiste odontogénico ortoqueratinizado, quiste odontogénico ortoqueratinizado.

\section{REFERENCES}

Barnes, L.; Eveson, J. W.; Reichart, P. \& Sidransky, D. (eds.). World Health Organization; International Agency for Research on Cancer. World Health Organization classification of tumors. Pathology and genetics of head and neck tumors. Lyon, IARC Press, 2005.

Brannon, R. B. The odontogenic keratocyst. A clinicopathologic study of 312 cases. Part I. Clinical features. Oral Surg. Oral Med. Oral Pathol., 42(1):5472, 1976.

Chuong, R.; Donoff, R. B. \& Guralnick, W. The odontogenic keratocyst. J. Oral Maxillofac. Surg., 40(12):797-802, 1982.

Donatsky, O.; Hjörting-Hansen, E.; Philipsen, H. P. \& Fejerskov, O. Clinical, radiologic and histopathologic aspects of 13 cases of nevoid basal cell carcinoma syndrome. Int. J. Oral Surg., 5(1):19-28, 1976.

Giuliani, M.; Grossi, G. B.; Lajolo, C.; Bisceglia, M. \& Herb, K. E. Conservative Management of a Large Odontogenic Keratocyst: Report of a Case and Review of the Literature. J. Oral Maxillofac. Surg., 64(2):308-16, 2006.

Kolokhytas, A.; Fernandes, R. P.; Pazoki, A. \& Ord, R. A. Odontogenic keratocyst: To decompress or not to decompress? A comparative study of decompression and enucleation versus resection/peripheral ostectomy. J. Oral Maxillofac. Surg., 65(4):640-4, 2007.

Leite, T. C.; Meirelles, J. V. \& Janini, M. E. R. Odontogenic keratocystic tumor: A clinical and histopathologic retrospective study based on the new WHO classification. Int. J. Odontostomat., 5(3):227-34, 2011.

Maurette, P. E.; Jorge, J.; de Moraes, M. Conservative Treatment Protocol of Odontogenic Keratocyst: A Preliminary Study. J. Oral Maxillofac. Surg., 64(3):37983, 2006.
Mendes, R. A.; Carvalho, J. F. \& van der Waal, I. Characterization and management of the keratocystic odontogenic tumor in relation to its histopathological and biological features. Oral Oncol., 46(4):219-25, 2010.

Myoung, H.; Hong, S. P.; Hong, S. D.; Lee, J. I.; Lim, C. Y.; Choung, P. H.; Lee, J. H.; Choi, J. Y.; Seo, B. M. \& Kim, M. J. Odontogenic keratocyst: Review of 256 cases for recurrence and clinicopathologic parameters. Oral Surg. Oral Med. Oral Pathol. Oral Radiol. Endod., 91(3):32833, 2001.

Oda, D.; Rivera, V.; Ghanee, N.; Kenny, E. A. \& Dawson, K. H. Odontogenic Keratocyst: The Northwestern USA Experience. J. Contemp. Dent. Pract., 1(2):60-74, 2000.

Philipsen, H. P. On keratocysts in the jaws. Tandlaegebladet, 60:963-80, 1956.

Correspondence to:

Ellen Cristina Gaetti Jardim

America do Norte St, 373

Jardim Jussara

Zip Code: 16021-295

Araçatuba, Sao Paulo

BRAZIL

Email: ellengaetti@gmail.com

Received: 22-05-2012

Accepted: 28-01-2013 